\title{
A Randomized Trial of Rofecoxib for the Chemoprevention of Colorectal Adenomas
}

\author{
JOHN A. BARON, ${ }^{*}$ ROBERT S. SANDLER, ${ }^{\ddagger}$ ROBERT S. BRESALIER, ${ }^{\S}$ HUI QUAN," ROBERT RIDDELL," ANGEL LANAS," \\ JAMES A. BOLOGNESE," BETTINA OXENIUS," KEVIN HORGAN," SUSAN LOFTUS," and DION G. MORTON* \\ *Departments of Medicine and Community and Family Medicine, the Norris Cotton Cancer Center, Dartmouth Medical School, Hanover, New Hampshire; \\ ${ }^{\ddagger}$ Department of Medicine, University of North Carolina, Chapel Hill, North Carolina; "Merck Research Laboratories, West Point, Pennsylvania; "Department of \\ Pathology, Mount Sinai Hospital, Toronto, Canada; * Department of Surgery, University of Birmingham, Birmingham, United Kingdom; "Department of Medicine, \\ Instituto Aragones de Ciencias de la Salud, University Clinic Hospital, Zaragoza, Spain; and the ${ }^{\S}$ Department of Gastrointestinal Medicine and Nutrition, University of \\ Texas, MD Anderson Cancer Center, Houston, Texas for the APPROVe TRIAL INVESTIGATORS
}

See editorial on page 2003; CME quiz on page 1971.

Background \& Aims: In human and animal studies, nonsteroidal anti-inflammatory drugs have been associated with a reduced risk of colorectal neoplasia. Although the underlying mechanisms are unknown, inhibition of cyclooxygenase (COX), particularly COX-2, is thought to play a role. We conducted a randomized, placebo-controlled, doubleblind trial to assess whether use of the selective COX-2 inhibitor rofecoxib would reduce the risk of colorectal adenomas. Methods: We randomized 2587 subjects with a recent history of histologically confirmed adenomas to receive daily placebo or $25 \mathrm{mg}$ rofecoxib. Randomization was stratified by baseline use of cardioprotective aspirin. Colonoscopic follow-up evaluation was planned for 1 and 3 years after randomization. The primary end point was all adenomas diagnosed during 3 years' treatment. In a modified intent-to-treat analysis, we computed the relative risk of any adenoma after randomization, using Mantel-Haenszel statistics stratified by low-dose aspirin use at baseline. Results: Adenoma recurrence was less frequent for rofecoxib subjects than for those randomized to placebo $(41 \%$ vs $55 \%$; $P<$ .0001; relative risk [RR], 0.76; $95 \%$ confidence interval [CI], $0.69-0.83)$. Rofecoxib also conferred a reduction in risk of advanced adenomas $(P<.01)$. The chemopreventive effect was more pronounced in the first year (RR, $0.65 ; 95 \% \mathrm{CI}$, $0.57-0.73$ ) than in the subsequent 2 years (RR, $0.81 ; 95 \% \mathrm{CI}$, $0.71-0.93$ ). As reported previously, rofecoxib was associated with increased risks of significant upper gastrointestinal events and serious thrombotic cardiovascular events. Conclusions: In this randomized trial, rofecoxib significantly reduced the risk of colorectal adenomas, but also had serious toxicity.

$\mathrm{E}$ pidemiologic studies, ${ }^{1,2}$ experimental studies in animals, $, 3,4$ and clinical trials in human beings ${ }^{1,2,5-8}$ have all shown that nonsteroidal anti-inflammatory drugs (NSAIDs) have antineoplastic effects in the colon and rectum. These drugs exert anti-inflammatory actions through inhibition of cyclooxygenase $(\mathrm{COX})$, the enzymes that produce prostaglandins. ${ }^{9} \mathrm{Al}-$ though the mechanisms underlying the antineoplastic NSAID effects are not clear, it is likely that inhibition of one isoform of COX, COX-2, is involved. ${ }^{10}$ Consequently, selective inhibitors of COX-2 are natural candidates for chemoprevention, possibly more effective than nonselective NSAIDs, and with lower gastrointestinal toxicity. ${ }^{11,12}$

Adenomas are recognized precursors to most colorectal cancers, and the epidemiology of adenomas closely resembles that for colorectal cancer itself. ${ }^{13}$ Prevention of adenomas is likely to prevent colorectal cancer, and adenomas have been used widely as an end point in colorectal chemoprevention trials. To test the hypothesis that COX-2 inhibition exerts chemopreventive effects in the large bowel, we conducted a randomized trial of the selective COX-2 inhibitor rofecoxib for the prevention of colorectal adenomas.

\section{Materials and Methods}

The Adenomatous Polyp PRevention On Vioxx (APPROVe) trial was a randomized, double-blind, placebo-controlled trial of the efficacy of oral rofecoxib, $25 \mathrm{mg} /$ day, to prevent colorectal adenomas. For regulatory purposes, the main study hypothesis was that 3 years of treatment with rofecoxib would reduce the adenoma risk among higher-risk subjects, that is, those with at least one of the following at baseline: an adenoma $1 \mathrm{~cm}$ or greater in estimated diameter, an adenoma with villous or tubulovillous histology, 2 or more adenomas, age younger than 55 years at first colorectal adenoma diagnosis, or reported history of colorectal cancer among first-degree relatives. From recent adenoma trials, ${ }^{7,14}$ we estimated that at least two thirds of participating subjects would have higher risk. The entire randomized population was the focus of prespecified secondary analyses. Other secondary hypotheses addressed adenoma occurrence in the first year of treatment, as well as that in the subsequent 2 years.

Abbreviations used in this paper: APPROVe, Adenomatous Polyp PRevention On Vioxx; $\mathrm{Cl}$, confidence interval; COX, cyclooxygenase; NSAID, nonsteroidal anti-inflammatory drug; RR, relative risk.

(C) 2006 by the AGA Institute

0016-5085/06/\$32.00

doi:10.1053/j.gastro.2006.08.079 


\section{Recruitment, Randomization, and Treatment}

We recruited men or women at least 40 years old with at least 1 histologically confirmed large-bowel adenoma within 12 weeks of study entry and no known polyps remaining in the bowel after complete colonoscopy. Exclusion criteria included the following: familial adenomatous polyposis or hereditary nonpolyposis colorectal cancer, history of a colorectal adenoma before age 35 , small- or large-bowel resection or inflammatory bowel disease, cancer within the 5 years before enrollment (except for nonmelanoma skin cancer), anticipated need for chronic NSAID therapy (including highdose aspirin), evidence of occult gastrointestinal bleeding (1 or more of 3 stool Hemoccult [Beckman Coulter, Inc., Palatine, IL] screens positive), blood pressure higher than 165/95 mm Hg, angina or congestive heart failure with symptoms at minimal activity, history of myocardial infarction or coronary revascularization within the past year, or history of stroke or transient ischemic attack within the past 2 years.

Because aspirin's chemopreventive effects might have interfered with the study of those of rofecoxib, we initially excluded subjects who regularly used aspirin. However, soon after the study began we relaxed this exclusion to allow up to $20 \%$ of subjects to use low-dose ( $\leq 100 \mathrm{mg} /$ day) aspirin for cardiovascular prevention. This change avoided discouraging cardioprophylaxis in subjects who needed it, and also enhanced generalizability and eased recruitment. The protocol initially included randomization to placebo, $25-\mathrm{mg}$ rofecoxib, or 50-mg rofecoxib arms. The last of these was dropped to accommodate the increased numbers of subjects needed when aspirin use was allowed. According to the analysis plan adopted at that time, the 25 subjects who had been randomized to this arm were not included in any analyses.

Enrollment occurred from February 2000 to November 2001 at 108 centers in 29 countries (see Appendix). An institutional review board for each center approved the study, written informed consent was obtained from all subjects, and an independent safety and monitoring board oversaw the trial. A study pathologist examined slides from each subject to confirm eligibility. According to the prespecified analysis plan, subjects not confirmed to have an adenoma at baseline were omitted from efficacy analyses, but were included in safety analyses.

At study enrollment, subjects entered a 6-week, single-blind, placebo run-in. Patients who took at least $80 \%$ of run-in tablets and were deemed suitable were assigned randomly to active study tablets or an identical-appearing placebo daily for 3 years. The computer-derived randomization was stratified by clinical center and low-dose aspirin use, with a blocking factor of 2 . Patients, investigators, and study monitoring staff were blinded to treatment allocations.

\section{Follow-Up Evaluation}

In-person visits occurred at randomization and weeks $4,17,35,52,69,86,104,121,138,156$, and 158 or after treatment discontinuation. Recent medical events and medications used were recorded at each visit. Mortality was tracked for the entire treatment period; other adverse events were recorded and evaluated by the blinded investigators for subjects on-treatment and for 2 weeks after the last study dose. Follow-up colonoscopy was planned for 1 and 3 years after randomization. Patients who discontinued study therapy were encouraged to return for scheduled colonoscopies. In 2003, the protocol was amended to include a year-4 follow-up colonoscopy to assess adenoma occurrence after cessation of study therapy. At each study colonoscopy, we asked the endoscopists to record the estimated size and location of all polyps and mucosal lesions suspicious for neoplasia. Endoscopists also were asked to photograph cecal landmarks and each polyp (with adjacent biopsy forceps to facilitate estimation of size). We also retrieved information regarding other large-bowel endoscopies that occurred during the study. Each lesion was removed and examined histologically by the study pathologist. Subjects were counseled regularly regarding avoidance of aspirin and other NSAIDs; lists of products containing these agents were provided at study entry, along with a list of analgesic/antipyretic drugs that did not contain NSAIDs. Acetaminophen was distributed for treatment of minor febrile illnesses and pain. Blinded adjudication committees assessed possible thrombotic cardiovascular and significant upper gastrointestinal events, including perforations, ulcers, obstructions, and bleeds.

\section{Statistical Analysis}

A modified intention-to-treat analysis was conducted, including all randomized subjects with a follow-up colonoscopy. The primary study outcome was the cumulative proportion of subjects with 1 or more colorectal adenomas detected during the 3-year treatment. A time-to-event approach was used in the overall analysis, with event times grouped into 2 intervals corresponding to the years 1 and 3 follow-up colonoscopies. To allow time for scheduling and completion of the year 1 colonoscopy, the first year was set at 65 weeks; the second 2 years were taken to be the time after the first year examination through 3 years plus 3 months. The treatment effect was assessed by a log-rank test stratified by baseline aspirin use. Cumulative incidence within strata of baseline aspirin use was calculated using a Kaplan-Meier estimate over the 2 time periods. The overall cumulative incidence for each treatment group, and risk ratios with $95 \%$ confidence intervals (CIs), were calculated using MantelHaenszel weights over strata of baseline aspirin use. Prespecified secondary outcomes were the numbers of large-bowel adenomas and advanced adenomas: tubulovillous adenomas (25\%-75\% villous features), villous adenomas ( $>75 \%$ villous), large adenomas $(\geq 1 \mathrm{~cm})$, those with high-grade dysplasia, or invasive cancer. Separate analyses also were conducted for the left colorectum (descending colon/sigmoid colon/rectum) and the right colon (the remainder of the bowel). Polyps with missing pathology because of lost or unretrieved specimens were omitted from the analysis. Differences between the treatment relative risks (RRs) in year 1 and years 2-3 were tested using a normal approximation to the binomial distribution of counts of patients with and without adenomas. This analysis included only subjects with colonoscopies in both time periods. The test compared the treatment difference in proportions with adenomas in year 1 and years $2-3$, taking into account within-subject correlation of risk. ${ }^{15}$ Interactions of treatment effects with baseline characteristics were examined using weighted least squares to test for risk ratio homogeneity across subgroups. Proportional hazards 


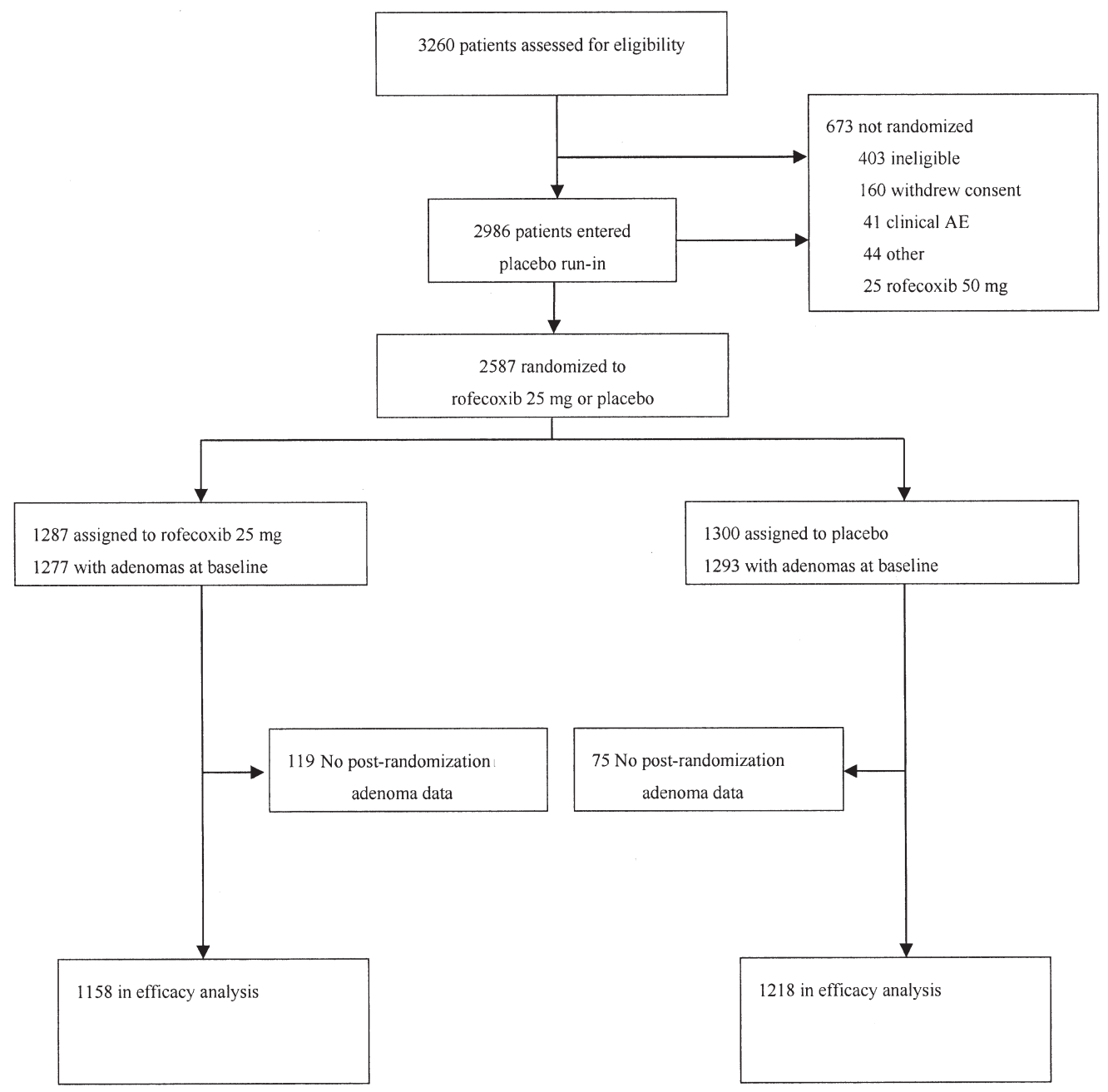

Figure 1. Enrollment, randomization, follow-up evaluation, and data analysis. The original study design included a rofecoxib $50-m g$ group; 25 patients were assigned to this treatment before it was decided not to proceed with this arm. AE, adverse event.

regression was used for between-treatment comparisons of risks of adverse events.

In designing the final protocol, we assumed that adenoma risk in placebo higher-risk subjects would be $35 \%$, that at most $20 \%$ of subjects would use low-dose aspirin, and that $80 \%$ of randomized subjects would be evaluable. For regulatory purposes, we designed the trial to have $90 \%$ power to detect a $32 \%$ reduction in adenoma risk with an $\alpha$ value of .0025 ; for scientific inference an $\alpha$ value of 0.05 was stipulated. Thus, we aimed to randomize 2428 subjects (1578 or more higher risk). By protocol, we did not plan to stop early for efficacy. $P$ values and CIs were 2-sided and were not adjusted for multiple testing. Follow-up data presented include all events recorded as of April 27, 2006.

\section{Results}

Overall, 3260 patients were screened for study; 2587 were randomized to rofecoxib $25 \mathrm{mg}$ or placebo (Figure 1). Seventeen subjects found not to have at least 1 colorectal adenoma on uniform pathology review were dropped from efficacy analyses, leaving 1277 subjects randomized to rofecoxib and 1293 randomized to placebo. There were no substantial differences between treatment groups in demographic, lifestyle, or clinical characteristics (Table 1). Overall, 2015 (78.4\%) subjects met the criteria for having higher risk.

In September 2004, 2 months before the anticipated end of the trial, APPROVe treatment was terminated on the advice of the External Safety and Monitoring Board ${ }^{16}$ because of a higher rate of cardiovascular events in the rofecoxib group. At that time, 2373 (92\%) subjects had either discontinued study agents or completed the planned 3-year treatment period. The remaining subjects were urged to undergo year-3 examinations, and those who wished to become unblinded were told their treatment assignments.

Reported compliance with the study protocol was excellent (Table 2). Even in the third year of the trial, more than $87 \%$ of subjects reported taking at least $90 \%$ of their tablets. Subjects also avoided higher-dose aspirin and other NSAIDs: reported use generally was well below $10 \%$ except in year-3. At least 1 study colonoscopy was performed for 1162 rofecoxib subjects (91.0\%) and 1219 placebo subjects (94.4\%). Ninety-five percent of the year- 1 colonoscopies and $94 \%$ of the year- 3 examinations permitted complete large-bowel visualization. 
Table 1. Baseline Patient Characteristics

\begin{tabular}{|c|c|c|c|c|}
\hline \multirow[b]{2}{*}{ Characteristic } & \multicolumn{2}{|c|}{ All subjects } & \multicolumn{2}{|c|}{ Higher-risk subjects } \\
\hline & Placebo $(\mathrm{N}=1293)$ & $\begin{array}{l}\text { Rofecoxib } 25 \mathrm{mg} \\
\quad(\mathrm{N}=1277)\end{array}$ & Placebo $(N=1001)$ & $\begin{array}{l}\text { Rofecoxib } 25 \mathrm{mg} \\
\quad(\mathrm{N}=1014)\end{array}$ \\
\hline Mean age, $y$ (range) & $59.4(40-86)$ & $59.4(40-96)$ & $58.0(40.0-86.0)$ & $58.1(40-86)$ \\
\hline Mean height, $\mathrm{cm}$ (range) & $170(133-199)$ & $170(137-198)$ & $170(133-198)$ & $170(137-198)$ \\
\hline Mean weight, kg (range) & $81.1(34-159)$ & $81.3(38-160)$ & $81.3(34.0-159)$ & $82.0(44.2-160)$ \\
\hline Male, n (\%) & $802(62.0)$ & $800(62.6)$ & $616(61.5)$ & $645(63.6)$ \\
\hline Caucasian, n (\%) & $1079(83.4)$ & $1074(84.1)$ & $845(84.4)$ & $865(85.3)$ \\
\hline United States, n (\%) & $667(51.6)$ & $655(51.3)$ & $508(50.7)$ & $522(51.5)$ \\
\hline Use of low-dose aspirin, $n(\%)^{a}$ & $203(15.7)$ & $213(16.7)$ & $148(14.8)$ & $158(15.6)$ \\
\hline Current cigarette user, n (\%) & $268(20.7)$ & $258(20.2)$ & $225(22.5)$ & $212(20.9)$ \\
\hline Alcohol use, n (\%) & $761(58.9)$ & $767(60.1)$ & $589(58.8)$ & $614(60.6)$ \\
\hline First-degree relative with colorectal cancer, n (\%) & $278(21.5)$ & $311(24.4)$ & $278(27.8)$ & $311(30.7)$ \\
\hline $2+$ baseline adenomas, $\mathrm{n}(\%)$ & $435(33.6)$ & $489(38.3)$ & $435(43.5)$ & $489(48.2)$ \\
\hline Baseline tubulovillous or villous adenoma, n (\%) & $176(13.6)$ & $151(11.8)$ & $176(17.6)$ & $151(14.9)$ \\
\hline Increased risk of colorectal neoplasia, $\mathrm{n}(\%)^{b}$ & $1001(77.4)$ & $1014(79.4)$ & $1001(100)$ & $1014(100)$ \\
\hline
\end{tabular}

aLow-dose aspirin use defined as $\leq 100 \mathrm{mg} /$ day.

${ }^{b}$ At least 1 of the following: an adenoma $1 \mathrm{~cm}$ or greater in estimated diameter, an adenoma with villous or tubulovillous histology, 2 or more adenomas, age younger than 55 years at the first diagnosis of colorectal adenoma, or reported first-degree family history of colorectal cancer.

In follow-up examinations, 5114 polyps were seen in 1598 subjects. Thirty-seven of 2874 polyps $(1.3 \%)$ in placebo subjects were not removed, and 46 of 2240 (2.1\%) in the rofecoxib group. Four rofecoxib and 1 placebo patient could not be included in the analysis because all of their polyps were not removed, leaving their adenoma recurrence status unclear. The study pathologist reviewed 2760 of 2874 polyps in placebo subjects and 2136 of 2240 for the rofecoxib group.

Table 2. Follow-Up Evaluation of Subjects

\begin{tabular}{lcc}
\hline & $\begin{array}{c}\text { Placebo } \\
(\mathrm{N}=1293)\end{array}$ & $\begin{array}{c}\text { Rofecoxib } \\
(\mathrm{N}=1277)\end{array}$ \\
\cline { 2 - 3 } & \multicolumn{2}{c}{ No. (\%) of subjects } \\
\hline No follow-up examination & $74^{a}(5.7)$ & $115^{a}(9.0)$ \\
Year-1 colonoscopy only & $108(8.4)$ & $113(8.9)$ \\
Year-3 colonoscopy only & $16(1.2)$ & $26(2.0)$ \\
Years 1 and 3 colonoscopy & $1094(84.6)$ & $1019(79.8)$ \\
Interim colonoscopy ${ }^{b}$ & $92(7.1)$ & $89(7.0)$ \\
Year-4 colonoscopy & $644(49.8)$ & $561(43.9)$ \\
Discontinued study treatment & $316(24.4)$ & $401(31.4)$ \\
Percentage taking study agents & & \\
$\quad \geq 75 \%$ of days ${ }^{c}$ & & \\
Year 1 & 91.6 & 86.9 \\
Year 2 & 92.5 & 91.7 \\
Year 3 & 93.9 & 93.1 \\
Percentage taking NSAIDs $>52$ & & \\
$\quad$ days & & 3.8 \\
Year 1 & 3.9 & 9.1 \\
Year 2 & 7.3 & 11.6 \\
Year 3 & 9.4 & \\
\hline
\end{tabular}

ane additional patient in the placebo group and 4 in the rofecoxib group who had a follow-up colonoscopy could not be included in the efficacy analysis because all their polyps were either not removed or were lost after removal from the mucosa.

${ }^{b}$ Number of patients who had 1 or more follow-up colonoscopies in addition to the year-1 and/or year-3 procedures.

${ }^{c}$ Among subjects remaining on study treatment.
During the 3-year treatment period, 646 of 1218 examined placebo subjects had 1 or more adenomas, as did 460 of 1158 randomized to rofecoxib (RR, 0.76; 95\% CI, 0.69-0.83, $P<$ .001) (Table 3). During year 1 , the RR was 0.65 (95\% CI, $0.57-0.73$ ); during years 2 and 3 it was 0.81 (95\% CI, 0.71-0.93; $P$ for difference $=.001)$. Findings for higher-risk subjects were almost identical (Table 3).

After randomization, 1 or more advanced adenomas was detected in 213 subjects in the placebo group and 141 in the rofecoxib group (RR, 70; 95\% CI, 0.58 to $0.86 ; P<.001$ ) (Table $3)$. As for all adenomas, the risk reduction seemed stronger in the first year. Colorectal cancer was diagnosed in 6 rofecoxib and 11 placebo patients (RR, 0.60; 95\% CI, 0.21-1.61). The risk of hyperplastic polyps was essentially identical in the 2 treatment groups in all study intervals (Table 3).

The reduced risk of adenomas with rofecoxib was similar in the right colon (RR, 0.66;95\% CI, 0.59-0.75) and the left colon/rectum (RR, 0.82; 95\% CI, 0.71-0.94), in men (RR, 0.72; 95\% CI, 0.65-0.80) and women (RR, 0.84; 95\% CI, 0.71-0.98), and in low-dose aspirin users (RR, 0.68; 95\% CI, 0.55-0.84) and nonusers (RR, 0.77; 95\% CI, 0.70-0.85). However, there was a suggestion that the chemopreventive effect of the drug may be less pronounced among subjects who had advanced adenomas at baseline (RR, 0.83; 95\% CI, 0.73-0.95) than in those without (RR, 0.70; 95\% CI, 0.62-0.79; unadjusted $P$ for interaction $=$ $.05)$.

As reported previously, during the treatment period the rofecoxib group experienced increased risks of thrombotic cardiovascular events ${ }^{16}$ (RR, 1.89; 95\% CI, 1.18-3.04) and of upper gastrointestinal perforation, obstruction, symptomatic ulcer, or bleeding ${ }^{17}$ (RR, 4.91; 95\% CI, 1.98-14.5) (Table 4). More generally, a higher proportion of rofecoxib patients had serious adverse events $(27.5 \%)$ than did placebo patients $(22.2 \%$; $P<$ .002). This excess was largely owing to the cardiovascular disorders previously described, ${ }^{16}$ but significantly more rofecoxib than placebo patients reported various serious adverse events categorized as metabolism and nutrition disorders, renal and urinary disorders, and musculoskeletal and connective tissue 
Table 3. Colorectal Polyp Occurrence After Randomization, by Treatment Group

\begin{tabular}{|c|c|c|c|c|c|c|c|c|c|c|c|c|}
\hline & \multicolumn{6}{|c|}{ Higher-risk subjects ${ }^{a}$} & \multicolumn{6}{|c|}{ All randomized subjects } \\
\hline & \multicolumn{2}{|l|}{ Placebo } & \multicolumn{2}{|l|}{ Rofecoxib } & \multirow[b]{2}{*}{ Risk ratio $^{b}$} & \multirow[b]{2}{*}{$P$} & \multicolumn{2}{|l|}{ Placebo } & \multicolumn{2}{|l|}{ Rofecoxib } & \multirow[b]{2}{*}{ Risk ratio } & \multirow[b]{2}{*}{$P$} \\
\hline & $\begin{array}{c}\mathrm{N} \text { with adenomas/ } \\
\text { colonoscopy }\end{array}$ & Risk $^{c}$ & $\begin{array}{c}\mathrm{N} \text { with adenomas/ } \\
\text { colonoscopy }\end{array}$ & Risk $^{c}$ & & & $\begin{array}{c}\mathrm{N} \text { with adenomas/ } \\
\text { colonoscopy }\end{array}$ & Risk $^{c}$ & $\begin{array}{c}\mathrm{N} \text { with adenomas/ } \\
\text { colonoscopy }\end{array}$ & Risk $^{c}$ & & \\
\hline \multicolumn{13}{|l|}{ All adenomas } \\
\hline Years 1-3 & $523 / 954$ & 56.5 & $383 / 929$ & 42.8 & $0.76(.69-.83)$ & $<.001$ & $646 / 1218$ & 54.6 & $460 / 1158$ & 41.3 & $0.76(.69-.83)$ & $<.001$ \\
\hline Year 1 & $382 / 940$ & 40.6 & $237 / 908$ & 26.1 & $0.64(.56-.73)$ & $<.001$ & $471 / 1202$ & 39.2 & $287 / 1132$ & 25.4 & $0.65(.57-.73)$ & $<.001$ \\
\hline $\begin{array}{l}\text { Years } 2 \text { and } 3 \\
\text { Advanced } \\
\text { adenomas }\end{array}$ & $298 / 869$ & 34.3 & $235 / 843$ & 27.9 & $0.81(.70-.93)$ & .004 & $363 / 1110$ & 32.7 & $278 / 1045$ & 26.6 & $0.81(.71-.93)$ & .002 \\
\hline Years 1-3 & $176 / 954$ & 19.0 & $122 / 929$ & 13.7 & $0.72(.58-.89)$ & .002 & $213 / 1218$ & 18.0 & $141 / 1158$ & 12.7 & $0.70(.58-.86)$ & $<.001$ \\
\hline Year 1 & $127 / 940$ & 13.5 & $71 / 908$ & 7.8 & $0.58(.44-.76)$ & $<.001$ & $152 / 1202$ & 12.7 & $86 / 1132$ & 7.6 & $0.60(.47-.77)$ & $<.001$ \\
\hline $\begin{array}{l}\text { Years } 2 \text { and } 3 \\
\text { Hyperplastic po }\end{array}$ & $68 / 869$ & 7.8 & $57 / 843$ & 6.8 & $0.86(.61-1.21)$ & .38 & $82 / 1100$ & 7.4 & $62 / 1045$ & 5.9 & $0.80(.58-1.10)$ & .17 \\
\hline Years 1-3 & $330 / 954$ & 35.7 & $310 / 929$ & 34.3 & $0.96(.85-1.09)$ & .52 & $412 / 1218$ & 34.9 & $385 / 1158$ & 34.2 & $0.98(.87-1.10)$ & .71 \\
\hline Year 1 & $214 / 940$ & 22.8 & $220 / 908$ & 24.2 & $1.06(.90-1.25)$ & .46 & $266 / 1202$ & 22.1 & 269/1132 & 23.8 & $1.07(.92-1.25)$ & .35 \\
\hline Years 2 and 3 & $191 / 869$ & 22.0 & $172 / 843$ & 20.4 & $0.93(.77-1.11)$ & .42 & $238 / 1110$ & 21.4 & $216 / 1045$ & 20.6 & $0.96(.82-1.13)$ & .65 \\
\hline
\end{tabular}

NOTE. $P$ values for differences between year 1 and years $2-3$ risks are as follows: all subjects: all adenomas, .001; advanced adenomas, .02; higher-risk subjects: all adenomas, .001; advanced adenomas, .009.

aAt least 1 of the following: an adenoma $1 \mathrm{~cm}$ or greater in estimated diameter, an adenoma with villous or tubulovillous histology, 2 or more adenomas, age younger than 55 years at the first diagnosis of colorectal adenoma, or reported first-degree family history of colorectal cancer.

${ }^{b}$ Mantel-Haenszel estimates, computed over strata of baseline aspirin use.

cMantel-Haenszel risks over the indicated time period.

disorders (supplementary material online at www.gastrojournal. org). Over the anticipated 3-year treatment period (as noted previously, 3 years and 3 months in duration), there were 24 deaths in the rofecoxib group and 18 among placebo subjects (RR, 1.35; 95\% CI, 0.73-2.49).

Of the 2157 subjects who had year- 3 colonoscopies 820 or more days after randomization, 1547 agreed to enter the colonoscopy extension and 1205 actually had a year-4 examination (Table 2). The risk ratio for all adenomas at that examination was 1.21 (95\% CI, 1.01-1.45, $P=.04)$. For advanced adenomas, it was .99 (95\% CI, 0.59-1.66). Among subjects without a previous postrandomization adenoma, these risk ratios were 1.36 (95\% CI, 1.01-1.85) and 1.63 (95\% CI, $0.64-$ 4.14), respectively. Compared with those who did not have the year-4 examination, the group that was examined included a higher proportion of subjects younger than 65 years old $(73.6 \%$ vs $67.2 \% ; P=.02)$, men $(65.4 \%$ vs $59.6 \% ; P=.002)$, and those at higher risk of colorectal cancer $(80.2 \%$ vs $76.8 \% ; P=.035)$. Of the subjects who underwent a year- 4 examination, 150 had been unblinded to treatment assignment (87 placebo, 63 rofecoxib).

\section{Discussion}

In this large, randomized, double-blind clinical trial, we found that rofecoxib significantly reduced the 3-year risk of recurrent adenomas among patients with a recent adenoma history. Risk reduction for advanced lesions was similar to that for all adenomas. There was a suggestion that subjects presenting with advanced adenomas may experience less benefit in terms of relative risk than those with small tubular adenomas only. The chemopreventive effect did not appear to differ according to characteristics or habits of the subjects, including use of low-dose aspirin. In the year after cessation of treatment, rofecoxib subjects experienced a slightly increased risk of any

Table 4. Numbers of Patients Experiencing Important Medical Events After Randomization

\begin{tabular}{|c|c|c|c|c|}
\hline \multirow{3}{*}{ Deaths $^{a, b}$} & Placebo $(\mathrm{N}=1300)$ & Rofecoxib $(\mathrm{N}=1287)$ & \multirow{3}{*}{$\frac{\text { Risk ratio }}{1.14(0.50-2.60)}$} & \multirow{3}{*}{$\begin{array}{l}P \\
.75\end{array}$} \\
\hline & \multicolumn{2}{|c|}{ No. of subjects (\%) } & & \\
\hline & $12(0.92)$ & $12(0.93)$ & & \\
\hline Hospitalization & $236(18.2)$ & $285(22.14)$ & $1.33(1.12-1.59)$ & .001 \\
\hline All cancer & $71(5.5)$ & $74(5.8)$ & $1.13(0.81-1.56)$ & .47 \\
\hline Colorectal cancer & $11(0.85)$ & $6(0.47)$ & $.60(0.22-1.61)$ & .31 \\
\hline Serious adverse event ${ }^{c}$ & $288(22.2)$ & $354(27.5)$ & $1.37(1.18-1.60)$ & $<.001$ \\
\hline Thrombotic cardiovascular events ${ }^{d}$ & $27(2.1)$ & $47(3.7)$ & $1.89(1.18-3.04)$ & .008 \\
\hline $\begin{array}{l}\text { Upper gastrointestinal symptomatic ulcers, } \\
\text { perforations, obstructions, or bleeding }\end{array}$ & $6(0.46)$ & $27(2.1)$ & $4.91(1.98-14.5)$ & $<.001$ \\
\hline
\end{tabular}

NOTE. Within 14 days of end of study treatment.

aDeaths associated with an adverse event that began within 14 days of end of study treatment.

${ }^{b}$ After prior publication, ${ }^{16} 4$ additional deaths were reported (2 rofecoxib, 2 placebo).

${ }^{c}$ Cancer, death, congenital anomaly/birth defect, hospitalization or prolongation of a hospitalization, drug overdose, or other event that was life-threatening or that led to persistent or significant disability/incapacity.

${ }^{d}$ After prior publication, ${ }^{16} 2$ additional events were reported (1 rofecoxib, 1 placebo). 
adenoma, but not of advanced adenoma. Patients treated with rofecoxib experienced more serious adverse events, including increased risks of thrombotic cardiovascular events and serious upper gastrointestinal events.

Extensive observational data strongly suggest that persistent use of nonselective NSAIDs reduces the risk of colorectal cancer and adenomas. Randomized trials of aspirin among patients with previous adenomas ${ }^{7}$ or colorectal cancer $^{8}$ also show a reduction in adenoma risk. In familial adenomatous polyposis, the nonselective NSAID sulindac caused the regression of existing adenomas, ${ }^{1,2}$ as striking as a $70 \%$ reduction in 1 study. ${ }^{18}$ Similar, although less marked, findings have been reported for rofecoxib and another COX2-selective NSAID, celecoxib. ${ }^{5,6}$

The protective effect of rofecoxib was seen in nearly all subgroups of patients, indicating a broad chemopreventive impact. Because interactions with many factors were assessed, it is possible that the smaller reduction in risk we observed among subjects with advanced adenomas at baseline was a chance finding. Alternatively, an advanced lesion may signal a mucosa particularly prone to carcinogenesis (and resistant to chemoprevention), or rofecoxib may have stronger effects on earlier stages of carcinogenesis. It is similarly unclear why rofecoxib subjects had a slightly higher risk of small tubular adenomas (but not advanced adenomas) in the posttreatment year. There is little indication of increased risks of colorectal cancer after cessation of NSAID use, but this issue seems not to have been considered for adenomas. Nonetheless, the trend of relative risks over time periods in our study may indicate that the chemopreventive effect of rofecoxib may diminish over time. Unfortunately, interpretation of our data regarding this point is complicated by the fact that only a minority of randomized subjects had the off-treatment colonoscopy and some of those subjects were unblinded.

The mechanisms by which rofecoxib-or other NSAIDsreduces risk of colorectal neoplasia are not clear. All NSAIDs disrupt prostaglandin synthesis by inhibiting cyclooxygenase. COX-2 in particular has been implicated in colorectal carcinogenesis, ${ }^{10,19}$ a hypothesis supported by our findings. However, mechanisms unrelated to COX-2 also may play a role. ${ }^{20}$ Indeed, the fact that $81 \mathrm{mg}$ of aspirin daily reduces adenoma risk suggests that COX-2 inhibition may not be required for NSAID chemoprevention because aspirin is relatively selective for COX-1.21

Our large trial recruited subjects from numerous countries across the world, suggesting that our results are generalizable. However, the trial had limitations. Small polyps may be missed on colonoscopy, ${ }^{22,23}$ and overlooked adenomas could have been observed in follow-up evaluation as incident lesions. If these occurred equally in the 2 treatment arms, they would have conservatively biased our effect estimates. However, rofecoxib could cause these polyps to regress, as sulindac, rofecoxib, and celecoxib do in familial adenomatous polyposis. ${ }^{1,2,5,6,18}$ Such regression could have been part of the effect we observed, and could be a partial explanation for the apparently stronger effects at year 1 than during later follow-up evaluation. Also, our study included only patients with a history of colorectal neoplasia, and it is possible that subjects without such a history would have a different response to rofecoxib.

Our findings clearly indicate that rofecoxib reduces the 3 -year risk of colorectal adenomas among patients with an adenoma history. Similar findings have been reported for celecoxib. ${ }^{24,25}$ Given the toxicity associated with the use of rofecoxib, it is unlikely to be attractive for chemoprevention, but it is tempting to conclude that sustained use of other NSAIDs would permit increased surveillance intervals (in the expectation of reduced risks of colorectal cancer) and reduce risks from polypectomy. However, even proven efficacy of these drugs would not automatically justify their wide use for chemoprevention. The cardiovascular effects of nonaspirin NSAIDs are not well understood, ${ }^{26}$ and serious gastrointestinal toxicities may be an issue. Potential toxicities of NSAIDs will need to be weighed against their benefits in the context of the risk reduction already provided by periodic surveillance colonoscopy and polypectomy. ${ }^{27,28}$

\section{Appendix}

The Steering Committee for the APPROVe trial consisted of John A. Baron, MD (Chair), Robert S. Bresalier, MD, Robert S. Sandler, MD, Robert Riddell, MD, Dion Morton, MD, Angel Lanas, MD, Bettina Oxenius, MD,* James A. Bolognese, MStat,* and Kevin Horgan, MD.*

The External Safety and Monitoring Board consisted of James Neaton, PhD (Chair), University of Minnesota, Marvin A. Konstam, MD, New England Medical Center, David Bjorkman, MD, University of Utah Health Sciences Center, Richard Logan MD, University of Nottingham School of Community Health Sciences, and Hui Quan, PhD,* Merck Research Laboratories.

*Nonvoting members.

The APPROVe Trial included the following clinical investigators: M. Aguilar, Clinica Aguilar Bonilla, San Jose, Costa Rica; P. Angus, Austin \& Repatriation Medical Centre, Heidelberg, Australia; N. Arber, Tel Aviv Sourasky Medical Center, Tel Aviv, Israel; J.M.P. Badia, Hospital Clinic I Provincial, Barcelona, Spain; R.D. Baerg, Tacoma Digestive Disease Center, Tacoma, Washington; H. Baistrocchi, Unidad de Aparato Digestivo Julio Dante Baistrocchi, Cordoba, Argentina; M.L. Barclay, Christchurch Hospital, Christchurch, New Zealand; C. Beglinger, University of Basel, Basel, Switzerland; G. Bianchi-Porro, Ospedale Luigi Sacco, Milano, Italy; T. Bolin, Prince of Wales Hospital, Randwick, Australia; R.M. Bostick, Palmetto Health South Carolina Cancer Center, Columbia, South Carolina; J. Bradbury, University of Birmingham, Birmingham, England; R.S. Bresalier, A.A. Dekovich, T. Ben-Menachem, S.K. Batra, Henry Ford Hospital, Detroit, Michigan; E. Bruun, J. Christiansen, Amtssygehuset i Herlev, Herlev, Denmark; C. Burke, Cleveland Clinic Foundation, Cleveland, Ohio; E. Butruk, Akademia Medyczna w Warszawie, Warsaw, Poland; L. Capurso, Azienda Ospedaliera San Filippo, Roma, Italy; J.P. Cello, San Francisco General Hospital, San Francisco, California; M. Chapman, Good Hope Hospital, Sutton Coldfield, England; S. Chaussade, 
Hospital Cochin Saint-Jacques, Paris, France; D.P. Cleland, Montreal General Hospital, Montreal, Canada; G. Costamagna, Universita Cattolica del Sacro Cuore, Di Clinica Chirurgica, Rome, Italy; P. Crone, Kobenhavns Amtssygehus i Glostrup, Glostrup, Denmark; E.V. Cutsem, Universitaire Ziekenhuizen KU, Leuven, Belgium; G.R. D'Haens, Imeldaziekenhuis, Bon Heiden, Belgium; W. Dekker, J. Ferwerda, Kennemer Gasthuis, Haarlem, The Netherlands; E. Dominguez-Munoz, Hospital de Conxo, La Coruna, Spain; D.S. Eskreis, R.E. Tepper, Long Island Clinical Research Associates, Great Neck, New York; R. Estela, Hospital Clinico San Borja-Arriaran, Santiago, Chile; M. Färkkilä, University Central Hospital, Helsinki, Finland; G.M. Fugarolas, J.F. deDios, Hospital Universitario Reina Sofia, Cordoba, Spain; A. Giacosa, Instituto Nazionale Per La Ricerca Sul Cancro, Genova, Italy; M.J. Goldstein, Long Island Gastro Intestinal Research Group, Great Neck, New York; F. Gomollon-Garcia, Hospital Universitario Miguel Servet, Zaragoza, Spain; P. Gandrup, Aalborg Syenhus, Aalborg, Denmark; A. Habr-Gama, Hospital das Clinicas da Faculdade de Medicina da Universidade de Sao Paulo, Sao Paulo, Brazil; C. Hall, University Hospital of North Staffordshire, Stoke on Trent, England; M. Haque, S. Parry, Middlemore Hospital, Auckland, New Zealand; R. Hardi, Metropolitan Gastroenterology Group, Chevy Chase, Maryland; W. Harford, VA Medical Center, Dallas, Texas; S.M. Harris, N.B. Vakil, Aurora Sinai Medical Center, Milwaukee, Wisconsin; P.R. Holt, D.P. Kotler, Saint Luke's-Roosevelt Hospital, New York, New York; P.A. Holt, Endoscopic Microsurgery Associates, Towson, Maryland; R.W. Hultcrantz, Karolinska Universitetssjukhuset-Solna, Stockholm, Sweden; S.H. Itzkowitz, Mount Sinai Medical Center, New York, New York; R.F. Jacoby, University of Wisconsin Medical School, Madison, Wisconsin; K.E.J. Jensen, Centralsygehuset Esbjerg Varde, Esbjerb, Denmark; J.F. Johanson, Rockford Gastroenterology Associates, Ltd, Rockford, Illinois; P.W. Jørgensen, Bispebjerg Hospital, Copenhagen, Denmark; K.E. Kim, University of Chicago Medical Center, Chicago, Illinois; P. Knoflach, AKH Barmh, Schwestern vom helligen Kreuz, Wels, Austria; M. Koch, Capital Gastroenterology Consultants, Silver Spring, Maryland; B. Koch, St Vincenz Krankenhaus, Datteln, Germany; A. Lanas, Instituto Aragones de Ciencias de la Salud, University Clinic Hospital, Zaragoza, Spain; M.R. Lane, Auckland City Hospital, Auckland, New Zealand; T.R. Liebermann, Radiant Research, Austin, Texas; M. Lukas, Univerzita Karlova, Charles University, Prague, Czech Republic; C.M. Schmitt, Southern Clinical Research, Chattanooga, Tennessee; F. Macrae, Cabrini Hospital, Malvern, Australia; E.E. Maiza, Hospital Jose Joaquin
Aguirre, Santiago, Chile; N.E. Marcon, Toronto, Canada; R.D. Marks, Alabama Digestive Research Center, Alabaster, Alabama; C.E. Martinez, Hospital Militar Central, Bogota, Colombia; R. McLeod, Mount Sinai Hospital, Toronto, Canada; K.R. McQuaid, VA Medical Center, San Francisco, California; G. Minoli, Ospedale Valduce Reparto, Como, Italy; N. Mirza, University of Birmingham, Birmingham, England; M. Montoro, Hospital San Jorge, Huesca, Spain; A. Montoya, Clinica Shaio, Bogota, Colombia; G. Morelli, Optimum Clinical Research, Inc, Montreal, Canada; D.G. Morton, Department of Surgery, University of Birmingham, Birmingham, United Kingdom, England; T.J. Myrhoj, J.R. Andersen, Hvidovre Hospital, Hvidovre, Denmark; A Nakad, Hospital Notre Dame, Tournai, Belgium; V. Narayen, Gastrointestinal Diagnostic Center, Baltimore, Maryland; Y. Niv, Rabin Medical Center, Petah Tikva, Israel; P.M. Pardoll, S. Scheinert, Center for Digestive Diseases, St. Petersburg, Florida; C. Phino, J.M. Soares, Celestial Ordem Terceira da Santissima, Porto, Portugal; I. Pokorny, Prerov, Czech Republic; J. Ponce-Garcia, Hospital Universitari La Fe Valencia, Valencia, Spain; T. Ponchon, Hospital Edouard Herriot, Lyon, France; J.H. Pressman, San Diego Digestive Disease Consultants, Inc, San Diego, California; V. Prochazka, Fakultni Nemocnice Olomouc, Olomouc, Czech Republic; J.M. Provenza, Louisiana Research Center, Shreveport, Louisiana; W.S. Putnam, Seattle Gastroenterology Associates, Seattle, Washington; E. Quintero-Carrion, Hospital Universitario De Canarias Tenerife, Santa Cruz de Tenerife, Spain; S. Radley, University Hospital Birmingham, Birmingham, England; J.P. Raufman, V. Raj, University of Arkansas for Medical Sciences, Little Rock, Arkansas; D.K. Rex, Indiana University Hospital, Indianapolis, Indiana; F.P. Rossini, M. Spandre, Azienda Sanitaria Ospedaliera, Torino Italy; R.I. Rothstein, Dartmouth Hitchcock Medical Center, Lebanon, New Hampshire; A.K. Rustgi, University of Pennsylvania, Philadelphia, Pennsylvania; R. Sandler, University of North Carolina at Chapel Hill, Chapel Hill, North Carolina; B. Schmeizer, Sunninghill Clinic, Sandton, South Africa; R.E. Schoen, UPMC Presbyterian Department of Medicine, Pittsburgh, Pennsylvania; T.T. Schubert, Allenmore Medical Center, Tacoma, Washington; H.I Schwartz, Miami Research Associates, Miami, Florida; E. Segal, Hospital General de Agudos Carlos G Durand, Buenos Aires, Argentina; F. Seow-Choen, K.W. Eu, Singapore General Hospital, Singapore; N.R. Shah, Philip J. Bean Medical Center, Hollywood, Maryland; N. Skandalis, Peripheral General Hospital, Athens, Greece; Y. Soon, University of Birmingham, Birmingham, England; P.L. Szego, Montreal, Canada; N. Toribara, Uni- 
versity of Colorado Health Sciences Center, Denver, Colorado; J. Torosis, GI Research, Redwood City, California; D.K. Turgeon, University of Michigan, Ann Arbor, Michigan; S.W. Van der Merwe, Pretoria, South Africa; R. VanStolk, C.W. Howden, Northwestern University, Chicago, Illinois; P. Vergauwe, Algemeen Ziekenhuis Groeninge, Kortrijk, Belgium; B. Vergeau, C. Nizou, Hopital d'Instruction des Armees, Paris, France; G. Winde, Klinikum Kreis Herford, Herford, Germany; J. Wolosin, M.W. Swaim, Regional Research Institute, Jackson, Tennessee; J.C. Wolper, P.L. Yudelman, Digestive Health Physicians, Fort Myers, Florida; B.C.Y. Wong, University of Hong Kong Queen Mary Hospital, Hong Kong; J.P. Wright, Kinsbury Hospital, Claremont, South Africa; A. Zambelli, Ospedale Maggiore Azienda Ospedaliera, Crema, Italy.

\section{Supplementary Data}

Supplementary data associated with this article can be found, in the online version, at doi:10.1053/j.gastro. 2006.08.079.

\section{References}

1. Baron JA. Epidemiology of non-steroidal anti-inflammatory drugs and cancer. Prog Exp Tumor Res 2003;37:1-24.

2. Thun MJ, Henley SJ, Patrono C. Nonsteroidal anti-inflammatory drugs as anticancer agents: mechanistic, pharmacologic, and clinical issues. J Natl Cancer Inst 2002;94:252-266.

3. Oshima M, Dinchuk JE, Kargman SL, Oshima H, Hancock B, Kwong E, Trzaskos JM, Evans JF, Taketo MM. Suppression of intestinal polyposis in Apc delta716 knockout mice by inhibition of cyclooxygenase 2 (COX-2). Cell 1996;87:803-809.

4. Reddy BS, Rao CV, Rivenson A, Kelloff G. Inhibitory effect of aspirin on azoxymethane-induced colon carcinogenesis in F344 rats. Carcinogenesis 1993;14:1493-1497.

5. Higuchi T, Iwama T, Yoshinaga K, Toyooka M, Taketo MM, Sugihara K. A randomized, double-blind, placebo-controlled trial of the effects of rofecoxib, a selective cyclooxygenase- 2 inhibitor, on rectal polyps in familial adenomatous polyposis patients. Clin Cancer Res 2003;9:4756-4760.

6. Steinbach G, Lynch PM, Phillips RK, Wallace MH, Hawk E, Gordon GB, Wakabayashi N, Saunders B, Shen Y, Fujimura T, Su LK, Levin B. The effect of celecoxib, a cyclooxygenase-2 inhibitor, in familial adenomatous polyposis. N Engl J Med 2000;342:19461952.

7. Baron JA, Cole BF, Sandler RS, Haile RW, Ahnen D, Bresalier R, Mckeown-Eyssen G, Summers RW, Rothstein R, Burke CA, Snover DC, Church TR, Allen JI, Beach M, Beck GJ, Bond JH, Byers T, Greenberg ER, Mandel JS, Marcon N, Mott LA, Pearson $\mathrm{L}$, Saibil F, van Stolk RU. A randomized trial of aspirin to prevent colorectal adenomas. N Engl J Med 2003;348:891-899.

8. Sandler RS, Halabi S, Baron JA, Budinger S, Paskett E, Keresztes R, Petrelli N, Pipas JM, Karp DD, Loprinzi CL, Steinbach G, Schilsky R. A randomized trial of aspirin to prevent colorectal adenomas in patients with previous colorectal cancer. [erratum appears in N Engl J Med 2003;348:1939.] N Engl J Med 2003; 348:883-890.

9. Vane JR. Biomedicine. Back to an aspirin a day? Science 2002; 296:474-475.

10. Marnett LJ, DuBois RN. COX-2: a target for colon cancer prevention. Annu Rev Pharmacol Toxicol 2002;42:55-80.
11. Silverstein FE, Faich G, Goldstein JL, Simon LS, Pincus T, Whelton A, Makuch R, Eisen G, Agrawal NM, Stenson WF, Burr AM, Zhao WW, Kent JD, Lefkowith JB, Verburg KM, Geis GS. Gastrointestinal toxicity with celecoxib vs nonsteroidal anti-inflammatory drugs for osteoarthritis and rheumatoid arthritis: the CLASS study: a randomized controlled trial. Celecoxib Long-term Arthritis Safety Study. JAMA 2000;284:1247-1255.

12. Bombardier C, Laine L, Reicin A, Shapiro D, Burgos-Vargas R, Davis B, Day R, Ferraz MB, Hawkey CJ, Hochberg MC, Kvien TK, Schnitzer TJ, Group VS. Comparison of upper gastrointestinal toxicity of rofecoxib and naproxen in patients with rheumatoid arthritis. VIGOR Study Group. N Engl J Med 2000;343:15201528.

13. Sandler RS. Epidemiology and risk factors for colorectal cancer. Gastroenterol Clin North Am 1996;25:717-735.

14. Baron J, Beach M, Mandel J, Van Stolk R, Haile R, Sandler R, Rothstein R, Summers M, Snover D, Beck G, Bond J, Greenberg E. Calcium supplements for the prevention of colorectal adenomas. N Engl J Med 1999;340:101-107.

15. Agresti A. An introduction to categorical data analysis. New York, NY: Wiley, 1996.

16. Bresalier RS, Sandler RS, Quan H, Bolognese JA, Oxenius B, Horgan K, Lines C, Riddell R, Morton D, Lanas A, Konstam MA, Baron JA, Adenomatous polyp prevention on Vioxx trial I. Cardio vascular events associated with rofecoxib in a colorectal adenoma chemoprevention trial. N Engl J Med 2005;352:10921102.

17. Baron JA, Sandler RS, Bresalier RS, Quan H, Riddell R, Lanas A, Bolognese JA, Oxenius B, Horgan K, Loftus S, Morton DG. A randomized trial of rofecoxib for the chemoprevention of colorectal adenomas. Gastroenterology 2006;131:1674-1682.

18. Giardiello FM, Hamilton SR, Krush AJ, Piantadosi S, Hylind LM, Celano P, Booker SV, Robinson CR, Offerhaus GJ. Treatment of colonic and rectal adenomas with sulindac in familial adenomatous polyposis. N Engl J Med 1993;328:1313-1316.

19. Dannenberg AJ, Altorki NK, Boyle JO, Dang C, Howe LR, Weksler BB, Subbaramaiah K. Cyclo-oxygenase 2: a pharmacological target for the prevention of cancer. Lancet Oncol 2001;2:544-551.

20. Shiff SJ, Rigas B. The role of cyclooxygenase inhibition in the antineoplastic effects of nonsteroidal antiinflammatory drugs (NSAIDs). J Exp Med 1999;190:445-450.

21. Taketo MM. Cyclooxygenase-2 inhibitors in tumorigenesis (part I). J Natl Cancer Inst 1998;90:1529-1536.

22. Rex DK, Cutler CS, Lemmel GT, Rahmani EY, Clark DW, Helper DJ, Lehman GA, Mark DG. Colonoscopic miss rates of adenomas determined by back-to-back colonoscopies. Gastroenterology 1997;112:24-28.

23. Hixson $\sqcup$, Fennerty MB, Sampliner RE, McGee D, Garewal H. Prospective study of the frequency and size distribution of polyps missed by colonoscopy. J Natl Cancer Inst 1990;82:1769_ 1772.

24. Bertagnolli MM, Eagle CJ, Zauber AG, Redston M, Solomon SD, Kim K, Tang J, Rosenstein RB, Wittes J, Corle D, Hess TM, Woloj GM, Boisserie F, Anderson WF, Viner JL, Bagheri D, Burn J, Chung DC, Dewar T, Foley TR, Hoffman N, Macrae F, Pruitt RE, Saltzman JR, Salzberg B, Sylwestrowicz T, Gordon GB, Hawk ET, APC Study Investigators. Celecoxib for the prevention of sporadic colorectal adenomas. N Engl J Med 2006;355:873-884.

25. Arber N, Eagle CJ, Spicak J, Racz I, Dite P, Hajer J, Zavoral M, Lechuga MJ, Gerletti P, Tang J, Rosenstein RB, Macdonald K, Bhadra P, Fowler R, Wittes J, Zauber AG, Solomon SD, Levin B, PreSAP Trial Investigators. Celecoxib for the prevention of colorectal adenomatous polyps. N Engl J Med 2006;355:885-895.

26. U.S. Food and Drug Administration. Analysis and recommendations for agency action regarding non-steroidal anti-inflammatory drugs and cardiovascular risk. 2005.

27. Loeve F, van Ballegooijen M, Snel P, Habbema JD. Colorectal cancer 
risk after colonoscopic polypectomy: a population-based study and literature search. Eur J Cancer 2005;41:416-422.

28. Robertson DJ, Greenberg ER, Beach M, Sandler RS, Ahnen D, Haile RW, Burke CA, Snover DC, Bresalier RS, McKeown-Eyssen G, Mandel JS, Bond JH, Van Stolk RU, Summers RW, Rothstein R, Church TR, Cole BF, Byers T, Mott L, Baron JA. Colorectal cancer in patients under close colonoscopic surveillance. Gastroenterology 2005;129:34-41.
Received July 17, 2006. Accepted August 28, 2006.

Address requests for reprints to: John A. Baron, MD, Evergreen, Suite 300, 46 Centerra Parkway, Lebanon, New Hampshire 03766. e-mail: John.A.Baron@Dartmouth.edu; fax: (603) 650-3473.

Supported by Merck Research Laboratories.

The authors are indebted to the study subjects for their cooperation and enthusiasm. 